\title{
Quaderni
}

QUADERNI Communication, technologies, pouvoir

89 | Hiver 2015-2016

Penser l'avenir : le CESTA, un think tank atypique

\section{Emmanuelle Danblon, Victor Ferry, Loïc Nicolas et Benoît Sans (dir), Rhétoriques de l'exemple. Fonctions et pratiques}

Cédric Passard

\section{(2) OpenEdition}

Journals

Édition électronique

URL : http://journals.openedition.org/quaderni/964

DOI : $10.4000 /$ quaderni.964

ISSN : 2105-2956

Éditeur

Les éditions de la Maison des sciences de l'Homme

Édition imprimée

Date de publication : 5 janvier 2016

Pagination : 109-111

Référence électronique

Cédric Passard, «Emmanuelle Danblon, Victor Ferry, Loïc Nicolas et Benoît Sans (dir), Rhétoriques de l'exemple. Fonctions et pratiques », Quaderni [En ligne], 89 | Hiver 2015-2016, mis en ligne le 05 janvier 2016, consulté le 25 septembre 2020. URL : http://journals.openedition.org/quaderni/964 ; DOI : https://doi.org/10.4000/quaderni.964 


\section{Compte rendu}

\section{Rhétoriques de l'exemple. Fonctions et pratiques.}

Emmanuelle Danblon, Victor Ferry, Loïc Nicolas et Benoît Sans (dir)

Presses Universitaires de Franche-Comté, Besançon, 2014

par Cédric Passard

IEP de Lille

CERAPS

1. Victor Ferry,

Benoît Sans

et Alice Toma

(dir), « Études

sur l'exemple »,

Diversité et ldentité

Culturelle en

Europe, 8/2, 2011.

2. Voir Aristote, Rhétorique, Paris, GF Flammarion, 2007, pp. 357-362

3. Chaïm Perelman, L'empire rhétorique. Rhétorique et Argumentation, Paris, Vrin, 1977, p. 119.
Poursuivant un travail déjà entamé dans un numéro spécial de la revue DICE ${ }^{1}$, l'équipe du Groupe de Recherches en Rhétorique et en Argumentation Linguistique (GRAL), qu'anime Emmanuelle Danblon à l'Université Libre de Bruxelles, propose, dans cet ouvrage, une réflexion pluridisciplinaire sur les usages, les pratiques et les fonctions de l'exemple. «Objet rhétorique par excellence ", l'exemple est un des moyens de persuasion les plus communs et identifié comme tel depuis, au moins, Aristote qui en a fait l'un des deux piliers (avec l'enthymème) du logos ${ }^{2}$. Pourtant, la tradition aristotélicienne elle-même a conduit à déprécier la preuve par l'exemple par rapport au raisonnement par déduction : parce qu'il procède par induction, l'exemple est, en effet, généralement considéré comme un argument faible qui montre plus qu'il ne démontre. Au contraire, les auteurs de ce volume refusent de ravaler l'exemple au rang de simple illustration et entendent en découvrir la rationalité propre. Dans l'introduction générale, les directeurs de l'ouvrage soulignent ainsi le « rôle de passeur » de l'exemple qui prétend offrir un accès au général via le particulier et qui porte donc toujours en lui une tension constitutive entre l'Un et le Multiple, entre le singulier et l'universel, entre l'identique et l'hétérogène. Comme le notait déjà Chaïm Perelman, précisément à son propos, « il s'agit de rechercher, à partir du cas particulier, la loi ou la structure qu'il révèle ${ }^{3} »$.

Analysant le statut des exemples historiques dans les premiers chapitres du livre I des Essais de Montaigne à la lumière notamment des traités de rhétorique antique, Francis Goyet, qui signe le premier article, observe ainsi que 
ces exemples ne présentent pas qu'un intérêt « ornemental » mais jouent, plus fondamentalement, le rôle de preuves à l'intérieur du raisonnement. La plupart des six contributions de l'ouvrage interrogent également, quoiqu'à partir d'objets et de corpus très divers, la fonction rhétorique et l'exemplarité même de l'exemple. S'il n'est pas possible ici de résumer l'ensemble de ces contributions, mentionnons celles, particulièrement intéressantes, d'Alain Rabatel et Marc Angenot. L'un et l'autre montrent que l'exemple peut revendiquer une valeur paradigmatique (rappelons qu'exemple se dit paradeigma en grec). Alain Rabatel explique bien comment un témoignage particulier, comme celui de Charlotte Delbo, rescapée d'Auschwitz, est en mesure de présenter un caractère exemplaire (au sens littéral du terme) qui permet de rendre intelligible un événement sans précédent mais lui-même « exemplaire d'une rupture de civilisation » : « avant même que puisse s'élaborer une distance analytique et réflexive, le récit en mode témoin offre une première approche, processuelle, cognitive, heuristique de l'inédit et de l'impensé » (p. 81). Dans le cadre de l'histoire des idéologies, Marc Angenot remarque que l'exemplum peut opérer de manière inverse, au sens où il vient incarner un récit déjà composé ou préparé avant lui. Angenot examine ainsi comment le personnage d'Alfred Dreyfus a pu servir à personnifier le modèle du « traître juif » élaboré bien en amont dans la littérature antisémite de l'époque ; l'exemple de Dreyfus fait ici apparaître la «fonction d'induction auto-réalisatrice » de l'idéologie.

Si les articles s'intéressent surtout au fonctionnement logique et rhétorique de l'exemple, signalons cependant la contribution, très stimulante, de Fabrice Clément qui questionne, pour sa part, l'efficacité persuasive de l'exemple en s'appuyant sur les neurosciences. Il montre que l'exemple véhicule des raccourcis heuristiques (du type «feeling of knowing ») qui peuvent déjouer la « vigilance épistémique » des individus pour élaborer un message convaincant ; autrement dit, l'exemple tire une grande partie de sa performance rhétorique et de sa force inductive au fait que « moins un traitement cognitif exige d'efforts, et plus il tend à donner l'impression que le contenu qui est traité 'va de soi'» (p. 79).

Les articles, denses et parfois techniques, sont tous de bonne facture mais supposent sans doute au lecteur d'être familiarisé avec l'approche rhétorique car, dans l'ensemble, ils restent le fait de spécialistes du langage ou d'analystes du discours. On peut regretter peut-être, à cet égard, que l'objectif 
affiché d'interdisciplinarité ne soit qu'en partie atteint, d'autant que, comme c'est souvent malheureusement le cas dans les ouvrages collectifs, les différentes contributions ne dialoguent finalement que peu entre elles, même si la rapide introduction tente de faire ressortir quelques problématiques communes. Cet ouvrage de qualité n'en reste pas moins à conseiller à tous ceux qui s'intéressent aux modalités de persuasion et d'argumentation dans le discours et aux formes de rationalité qu'elles mettent en œuvre. 
